\title{
Decoding the Visual Rhetoric: Memory and Trauma in Lynda Barry's One! Hundred! Demons!
}

\author{
Partha Bhattacharjee \& Priyanka Tripathi \\ Department of Humanties and Social Sciences, Indian Institute of Technology Patna, India. \\ Correspondence: E-mail: partha.bhattacharjeee1990@gmail.com
}

Received: September 2, 2018

Accepted: September 20, $2018 \quad$ Online Published: September 23, 2018

doi:10.5430/wjel.v8n2p37

URL: https://doi.org/10.5430/wjel.v8n2p37

\begin{abstract}
Memory is an important tool in Lynda Barry's One! Hundred! Demons! (2002) as she reconnoitres in non-linear fragments the personal trauma she faced while she was growing up. Layered into nineteen disjointed chapters, Barry's graphic narrative is an amalgamation of images, collages and photographs, often following the pattern of a scrapbook style that justifies not only the events drawn in her narrative but also the motive of visual rhetoric in comics where visual images communicate and concretize meaning. Initially published as web comics (slate.com), each chapter consists of hand-painted vignettes of multifarious themes which are directly or indirectly linked to Barry's life, covering from her childhood to adulthood. In the backdrop of these tools, techniques of visual rhetoric the objective of this paper is to investigate the form of the graphic narrative, the visual language employed in order to explore the traumatised childhood, memory and truth-telling in comics.
\end{abstract}

Keywords: Trauma, Memory, Collage, Visual Language

\section{Introduction}

Comics Studies emerges as a scholarly field in the second half of the $20^{\text {th }}$ century and gains its boost to reach the acme in the current century. Artists, illustrators, cartoonists across the borders put their best effort in order to highlight their emotions and experiences in the panels of the comics. Among all other sub-genres (cancer narratives, superhero, mythological, science fiction, adventure etc.), autobiographical comics emerges with American cartoonist Justin Green's Binky Brown Meets the Holy Virgin Mary (1972), following Art Spiegelman's Maus (serialized from 1980 to 1991). However, reading and analysing the visual narratives with comics theories is the primary concern for the researchers following the pioneering works of theorists like Scott McCloud, Thierry Groensteen, Bart Beaty, Benoît Peeters et al. Relating to Charles Hatfield's suggestions and analysis in his book Alternative Comics (2005), scholars and researchers found the emergence of autobiography in comics as the alternative genre to the rest of the mainstream comics. Prior to the contributions of Debbie Drechsler, Julie Doucet and Aline Kominsky-Crumb in the 1990s, Alison Bechdel, Lynda Barry, Phoebe Gloeckner et al. in the next decade exemplified how comics and graphic narrative can be seen as a medium of approach for the representation of complex trauma and post-memory, abused childhood and testimonies. Cartooning on own lived experience was supposed to be a taboo culture as it comprised the ignominious dimensions of life.

Twenty-first century is a witness to multifarious dimensions not only in the comics publishing industry but also in the Comics Studies. In the 1980s and the 1990s, the Do-It-Yourself Movement (DIY) had an impact on the artists that further pushed an exponential growth in the industry. On the one hand, artists and illustrators went ahead producing variegated genres in the panels and, on the other hand, researchers progressed with their analysis of the comics in conference or research papers. Andrew Kunka (2018) explains

"The emergence of Comics Studies as a scholarly field in the last part of the twentieth century has also helped to legitimize the comics medium in general while also raising certain works into canonical roles. Now, classes are regularly taught on autobiographical comics, special issues of scholarly journals and panels at academic conferences (if not entire conferences) have been dedicated to the genre, and scholarly anthologies and monographs have appeared to offer ways of reading and analyzing autobiographical comics. (p. 52)

Comics as a 'fragmentary' form bears the traces of trauma of the illustrators and connects its readers to engage in 
bridging the gap between the panels. Hillary Chute (2017) remarks on the relevance of comics and the relation between image and text - "As a verbal-visual art form, comics is inherently about the relationship of word and image, which is to say, about different ways of communicating. It makes readers aware of the limits... Its very grammar... evokes the unsaid, or inexpressible" (p. 34)

With an intention to reach a wider audience, comics creators emphasise upon portraying their over and over again as the body, being the site of violation, become the primary concern for the comics creators. During the underground comix movement in 1960s and 70s, most of the women illustrators were debarred from joining the movement. In dealing with the cancer narratives in comics, Martha Stoddard Holmes (2014) coins the term "graphic body studies" to define scholarship concerned with the representations of bodies in comics:

By graphic body studies, I mean a theory and analysis of graphic representations of embodied experiences and social identities, drawing on the work of disability studies and other body studies theories but attending to the specific attributes of a hybrid genre that draws words and writes pictures. (pp. 147-148)

Sexual violence, political violence and the disgust of it on psyche of a child becomes the subject matter of the autobiographic illustrators; Jane Tolmie (2013) begins her book with a beautiful critical aspect of why the sub-genre is an academic interest to the readers - "What is at stake in comic memoir and semi-autobiography is embodiment. Remembering a scene with the intent of rendering it in sequential art requires nonlinear thinking and engagement with physicality" (p. vii).

\section{Lynda Barry and her Contributions in Comics}

Lynda Barry (1956 - ), one of the leading cartoonists in America, practises comics and cartooning since her schooldays. In some of her interviews she discusses the contents of her comics and refers to it as the reflection of the 'trouble' in her life. Initially, she received negative responses from the readers because of engrossing the dark and disturbing contents in the panels however, later on, she found it weird that readers preferred to enjoy the funny moments of child abuse while her comics were sad in nature and tone. Barry's first book, Girls and Boys was published in 1981 under the supervision of independent publisher Real Comet Press. Her other notable contributions to autographics include Big Ideas (1983), Naked Ladies, Naked Ladies, Naked Ladies: Coloring Book (1984), Everything in the World (1986), The Fun House (1987), Down the Street (1989), Cruddy (Simon \& Schuster hardcover 1999), The Greatest of Marlys (2000), One! Hundred! Demons! (Sasquatch Books 2002), What It Is (2008) - to name a few. Barry experimented with the narrativization in comics; there is a shift in her style from her initial days of cartooning - while "The Red Comb" was illustrated in 'traditional four-panel comic strip', later narratives saw her experimenting with the earlier one as well as collage, colours and photographs. One! Hundred! Demons! contains two panels on each page, where the upper frame contains Barry as narrator and the lower contains Barry the protagonist. Moreover, the use of stark contrasting colours became a signature of Barry-esque style.

\section{Language and Visual Narrative in One! Hundred! Demons!}

"Visual rhetoric" owes its origin to the much broader and all-embracing rubric of "Visual Literacy'. The concept has been further sub-divided into three major categories: visual thinking, visual learning and visual rhetoric/communication. Comics and graphic narratives often convey the meanings through the use of illustrations and images which are used for the readers to visually think, visually learn and visually communicate with the panels in order to involve themselves in the meaning making-process. Hatfield's comment in his book Alternative Comics (2005) is very apt in this context - "Unlike first-person narration, which works from the inside out, describing events as experienced by the teller, cartooning ostensibly works from the outside in, presenting events from an (imagined) position of objectivity, or at least distance" (Italics in original, p. 115).

One! Hundred! Demons! (2002) published by Sasquatch Books is divided into nineteen sections, each named after a 'demon'. Critics often assumed it to be an explicit autobiography from the illustrator covering a chain of incidents while she was living in Seattle in the 1960s. Barry calls it "Autobifictionalography" and puts forth a question before the readers at the very advent of the narrative - "Are these stories true or false?" Even, on the copyright page, the reader is alerted "Please note: This is a work of autobifictionalography." A chronological glance of her career reflects that Barry shifted from using pen to that of brush and it is reflected in her initial illustration of herself - the left panel asks "Is it autobiography if parts of it are not true?" and the right panel further questions "Is it fiction if parts of it are?" Not only did she use the paint-brush, inkstick, but also she incorporated photograph of her own. These photographs in the collage were used to validate the opinion of critics and reviewers who would otherwise question the authenticity of the narratives and the comics.

While drawing memory as an art-form Barry subtly layers her day to day experiences in a collage writing style and 
firmly asserts of her writing being a "multilayered composition" (Chute, p. 113). Layering the past with the present delineates the presence of the author in the narrative. In autobiographical comics, the illustrators reminisce their own childhood experiences and put it in the narrative structure. There are two dimensions in the narrating techniques: first, while jotting down the 'personal memories', they need to create a framework in which they can manipulate their narratives. Elisabeth El Refaie in her book Autobiographical Comics: Life Writing in Pictures (2012) writes,

The self in all life writing can be said to be tacitly plural, including a divergence between, at the very least, the real-life I (the author), the narrating $I$ (the self who tells), and the experiencing $I$ (the self told about). (p. 53)

The second dimension is the appropriation of Philip Lejeune's concept - "autobiographical pact" which creates a subconscious illusion running undercurrent in the back of the mind of the readers that the storyteller, story-narrator and the protagonist in the story are the same person. While introducing the narrative, Barry's presence as a narrator reflects the space where she gets into a discourse with her readers and the protagonist Barry's words come in the bubble-boxes or speech-boxes. Her memoir and the presentation of "I" in the narrative contradict the conventional idea of presentation in memoir which generally prioritizes the coherent, unipolar and linear subjectivity. While dealing with narrative style of One! Hundred! Demons!, Susan Kirtley (2012) analyses

When collecting the strips for a book version, Barry fashions a scrapbook of sorts, employing this gendered, domestic form to frame her life stories with ephemera from childhood and artistic collages featuring glitter, ribbon, and trinkets. These shaped and constructed images of Barry's life focus on girlhood as mediated through her memory and her skills as a writer and artist, suggesting a vision that stresses an archival record of personal history as presented through the interposing lenses of time and technology. (p. 148)

Throughout the pages, Barry uses hand-written words (all in uppercase) often putting a digression by randomly making one word in lowercase and leaving the rest in uppercase. Going by the definition of visual semiotics this tendency of digression in the narrative is meant for hinting the readers of the symbolic nature of the word or to refer to the underlying meaning of the word. Another possible interpretation is that for the purpose of narrating the childhood experiences, she wanted to write the lexical portions in a way that it seems to be written by a child. Delving into the practice of panel transition in Barry's comics, Michelle White (2017) points out, "The compositions are simplified and flat, usually slapping two figures onto a background and letting them duke it out. This, combined with the horizontal progression of the eye, preserves the feeling of a comic strip."

Following the comics strips of Barry in One! Hundred! Demons!, the chronological linearity is missing as the narrative is oscillating between the childhood and adulthood and this discontinuity as a technique is employed to flash back and flash forth between the panels. The book opens with the chapter, "Head Lice/My Worst Boyfriend," structured on a page coloured with dull red containing Barry's disgust - "You talk talk talk about asinine memories like they mean something! You're shallow! You're poison! Do you really think I'm interested?" she stares at him disbelievingly and says, "Mom?!" (p. 21, p. 24). The phrase "asinine memories" establishes the nature of the book where 'memory' becomes the tool for the visual rhetorics. From the very outset, she portrayed her struggle with her identity. According to her illustrations, there were three members in her family including her; she was brought up by her mother whom she described as "unpredictable and quiet violent," (Barry, p. 91) and her grandmother with whom she had a good bondage. Lynda's drawing of her other women characters essentially avows that she had some physical dissimilarities from her Filipino 'foremothers' and culture about whom and which she had heard from her grandmother. An infelicitous discomfort and disconnection is traced from the very first chapter. Page 17 holds a panel where Lynda called herself as "cootie girl", referring not to the idea of 'Lice,' rather than an ongoing process of her social ostracism. In the first chapter itself, it is only once that her interaction with the Filipino children finds mention. Melinda L. de Jesús (2004) remarked

One Hundred Demons includes a number of comics that explore Barry's racial identity and family history including "The Aswang," "Head Lice/My Worst Boyfriend," "Dancing," "Girlness," "The Visitor," and "Common Scents," yet space considerations permit me discussion of only two comix which focus on aspects of mestizanes. (p. 229)

She grew fascinated with the bugs, probably because of a "certain kind of loneliness" (p. 17). Later on, friendship with other Filipino fellows drew the darker memory of her childhood wherein she recalls her mother's abusive words "You idiots!" (p. 19). To draw upon this demonic revelation, Barry uses the speech bubble with rough, sharp points protruding outside of a structure while the other bubbles are gentle and round shaped. Moreover, the word 'idiots' is underlined in box. One may conclude that Barry felt the expression of her mother so stingy that she marked it in her 
memoir. Later panels show that Barry imagined her mother in place of her boyfriend, Professor. She explained "I was wrong! It was someone from my past but it wasn't the Professor! It was ---" (24). An unfinished sentence like this is linked to the next panel where Barry's boyfriend has been replaced by her screaming mother - "You're shallow! You're poison! Do you really think I'm interested?" (underlined in original, p. 24).

While analysing the autobiographical comics and the language of it one of the main concerns is towards the analysis of the gutters as its the space where the writers or the illustrators can connect immensely with their readers. These spaces are left to be bridged by the readers in order to make an appropriate meaning not only out of the content analysis of the illustrations but also the structural layout of it. Before introducing the narrative to the readers, Barry puts a page wherein she wants her readers to write some message. Perhaps 'Gutter' means the gap between the consecutive panels. Scott McCloud explains in his Understanding Comics (1994) that gutter is the "space between the panels" (p. 66). He writes, Comics panels "fracture both time and space, offering a jagged, staccato rhythm of unconnected moments" (p. 67), but 'Closures' "connect these moments and mentally construct a continuous, unified reality," (p. 67) thereby giving the opportunity for the readers to generate a meaning out of the non-linearity of the plot. Gillian Whitlock (2006), while delving deep into the cruxes of autobiographical comics which she often termed as "autographics," pushed the boundaries of McCloud's concept. She added "meaning [is] produced in an active process of imaginative production whereby the reader shuttles between words and images, and navigates across gutters and frames, being moved to see, feel, or think differently in the effort of producing narrative closure" (Whitlock, p. 978). The concluding frames of the first chapter serve as the Closure as they insinuate Barry's realization of her mother as well as her boyfriend. He treated her the same way her abusive mother did in her earlier days. While finding meaning from the panels, one mustn't forget to emulate Charles Hatfield's remark in this regard wherein he states that comics "are not mere visual displays that encourage inert spectatorship but rather texts that require a reader's active engagement and collaboration in making meaning" (2005, p. 33).

The second chapter, "Lost Worlds," explicitly draws the dark memories of her childhood. Before reading the next demon, Barry puts a collage for her readers to understand the chaotic past of her life. These collages at the beginning of the chapters serve as the "interludes" (Graphic Women, p. 110) in the words of Hillary Chute. "Lost Worlds" begins with her memories of 'kick-ball' playing with children in the streets of her neighbourhood. The associated panels show the shouting of the children at each other as the speech bubbles are put together. In the next page, Barry differentiates herself from the other children with her bushy red hair. She encountered the darkness in her life as she explained metonymically, "There was something about the pools of street light, and the way the darkness surrounded us" (p. 32). One of the narrative structures that the readers of Barry would find out is the use of gutter used as a bridge to leap across time - a bridge to fill the gap of past and present. Two panels on page 33 demonstrate it in a striking way - Barry writes, “This was long before I grew up and found out you can't see very much from an airplane window. Big things, yes, but the little things are lost" (p. 33). In Lynda Barry: Girlhood through the Looking Glass, Susan Kirtley (2012) remarked that One Hundred Demons can be read as Barry's "idea of a dark, disturbing childhood from which the narrator ultimately survives, utilizing her own creative impulses to emerge victorious over the demons" (p. 148).

Pertaining to visual rhetoric, the most crucial chapter for analysis can be chapter six, "Resilience," for it explores the sexual trauma that occurred during her girlhood. Barry explored the nuances of girlness, sexuality, and trauma, with her depiction of the transition from being a girl to being a teenager. At one point of time in her girlhood, Barry seems to be sexually harassed and it is reflected in her voice implicitly. Page 65 highlights the point when Barry, the narrator, said "When I was still little, bad things had gone on, things too awful to remember but impossible to forget. When you put something out of your mind, where does it go? Dark ghosts in limbo moved me around. I didn't know how to fight them" (p. 65). This sexual trauma kept haunting her mind and as a result of which her representation of the memory gets fractured and fragmented. This haunting even provoked her to wish for her own death to God (p. 70). While the girl Barry wished for her death, the narrator Barry defined the word 'resilience' in a subtle way "This ability to exist in pieces is what some adults call resilience. And I suppose in some way it is a kind of resilience, a horrible resilience that makes adults believe children forget trauma" (p. 70). The chapter closes with a striking note - girl Barry sat with her doll in the flower garden (striking enough is the similarity between the depiction of girl Barry and the doll) when a man came to her and said "Hey there, sweetheart. Do you and your dolly want to go for a ride?" (p. 72). The illustration of the man is quite in suspense as it is drawn in a way it assumes that the body is cut because of framing. It does not provide the identity of the man. He holds a cigarette in her left hand. The chapter ends with stark statement "CAN'T remember can't FORGET" (Barry, p. 62) which has a connection at the very beginning of the chapter. The first page of the chapter has a collage; Chute pointed out that "Between the two images of her - one photographic, one drawn; one toddler, one adolescent; one smiling, one gloomy - is a window, whose 
twinned panes proffer the dilemma the story undertakes" (p. 116-7).

Often distancing her from the mainstream comics whether it is content or form, Barry's choice of subject and form becomes an interesting area for the readers and the researchers to be interpreted. "Hate," another chapter in One! Hundred! Demons!, Barry discloses her childhood experiences of hatred towards her friends Literally, Barry depicted the anger and the hate she used to feel for her fellow classmates (Barry, p. 76). The subject matter remains gloomy and negative per se. She fills the background of the panel with bold and bright colors - yellow and blue. This is where she puts a contradiction where visual and textual content do not sync in, rather they maintain themselves as individual features. "The medium of comics is cross-discursive because it is composed of verbal and visual narratives that do not simply blend together, creating a unified whole, but rather remain distinct" (Chute \& DeKoven, p. 769).

\section{Trauma in Autobiofictionalographical Comics}

One cannot analyse the trauma in the panels without referring to Cathy Caruth's seminal work in 1996, Unclaimed Experience: Trauma, Narrative, and History in which she focuses on the difficulties of jotting down the traumatic memory. Registering the traumatised past with an 'experienced' eye by recalling it all over again bruises the mind of the illustrator and erupts a memory that she disgusts to remember in the present self. Caruth substantiates this traumatic memory as "not a simple memory" (p. 151) in another volume, Trauma: Explorations in Memory (1995). The traumatized individual is disturbed with the memory as "the experience of [the] trauma repeats itself, exactly and unremittingly ... against his [or her] very will" (Unclaimed, p. 2). There are diverse dimensions of trauma engulfed the panels of One! Hundred! Demons! The demonic nature of Barry's childhood surroundings often puzzles her memory and thereby, there is a non-linearity in the sequence. "One Hundred Demons includes a number of comics that explore Barry's racial identity and family history including "The Aswang" "Head Lice/My Worst Boyfriend," "Dancing," "Girlness," "The Visitor," and "Common Scents" (p. 229) - writes Melinda. While analyzing Lynda's trauma due to the social exclusion and ostracization, Melinda pointed out

"Common Scents" and "The Visitor" illustrate how a white mestiza like Lynda grows into awareness and understanding of racial difference and its connotations. I explore how Barry's delineation of Lynda's sense of alienation, both within her own family and socially, depicts American adolescent angst and the search for identity but also highlights the process of racial formation in the US and its effects upon Filipina/American mestiza identity. (p. 229)

Barry's artistic portrayal of trauma regarding the establishment of identity has rubbed some of the contemporary artists like Debbie Drechsler, Alison Bechdel, Marjane Satrapi et al. who not only focussed on the experiences of their girlhood, but also adopted different styles of illustration. Barry's style of attaching the photographs of items she previously illustrated in the book is a unique way of giving answers to those who generally question the validity and the authenticity of the comics. Moreover, the photographs play the role of paratext in the narrative. Gérard Genette in the article "Introduction to the Paratext" (Spring, 1991) explains that paratext is what "rarely appears in its naked state, without the reinforcement and accompaniment of a certain number of productions, themselves verbal or not, like an author's name, a title, a preface, illustrations" (p. 261).

The two Lyndas are overlapping on each other in the narrative - one the girl Lynda and the other the adult one. A pattern follows when the readers find that the some of the earlier chapters are based on Barry's girlhood while the latter ones are on adulthood. The chapters, "Dancing," "Dogs," and "Common Scents", together cover Barry's life in an almost chronological order. In the article "A Graphic Self," Rocio Davis notes that in comics "the process of memory often involves the symbolic interrogation of particular artifacts, sensory details like the taste of specific food or the smell of a childhood home, brief conversations or episodes that resound emotionally in the author's memory" (p. 268)

In the chapter "Girlness," Barry explains her own strained relationship to femaleness and how it has been shaped by race, class. She states "the narration wonders, "If I had these things, would I have been a girlish girl too?" (185)." Kirtley rightly pointed out that "Barry also links her ambivalence over girlness to the legacy of her mother, who was "quite feminine" and depicts brushing her long black hair, with conspicuous red fingernails and a flower-print dress... The older, adult narrator speculates that her mother must also have been jealous, particularly since her childhood in the Philippines was so "miserable". (p. 172)

\section{Conclusion}

Not only with the lexical contents but also with the visual contents and unorthodox narrative style, Barry pushed the boundaries of a conventional autobiographical narrative, widening her horizon that can be of interest and 
inquisitiveness both to its readers. One! Hundred! Demons! revisits Barry's tension of the traumatic past. Her innocence is trapped in between the panels and collages of demons which immediately hurl her to attain adulthood. In a nutshell, the 'demons' in the text are not just the demons that she wishes to portray rather they are the metaphoric demons she wishes to portray with an intention to purgate out of the pain she experiences in her past.

\section{References}

Caruth, C. (1995). Trauma: Explorations in memory. Baltimore: Johns Hopkins University Press.

Caruth, C. (1996). Unclaimed Experience: Trauma, narrative, and history. Baltimore, MD: Johns Hopkins University Press.

Chute, H., \& DeKoven, M. (2006). Introduction: Graphic Narrative. Modern Fiction Studies, 52(4), 767-78.

Chute, H. L. (2010). Graphic women: Life narrative and contemporary comics. New York: Columbia University Press.

Chute, H. L. (2017). Why comics?: From underground to mainstream. New York: HarperCollins.

Davis, R. G. (2005). A Graphic Self. Prose Studies, 27(3), 264-279. https://doi.org/10.1080/014403500223834

Genette, G., \& Maclean, M. (1991). Introduction to the Paratext. New Literary History, 22(2), 261-272. https://doi.org/10.2307/469037

Hatfield, C. (2005). Alternative comics. Jackson: University Press of Mississippi.

Holmes, M. S. (2013). Cancer comics: Narrating cancer through sequential art. Tulsa Studies in Women's Literature, 33(1), 147-162. The University of Tulsa. Retrieved August 24, 2018, from Project MUSE database.

Jesús, M. L. de. (2004). Liminality and Mestiza consciousness in Lynda Barry's “One Hundred Demons". MELUS, 29(1), 219-252. https://doi.org/10.2307/4141803

Kirtley, S. E. (2012). Lynda barry: Girlhood through the looking glass. Jackson: University Press of Mississippi.

Kunka, J. A. (2018). Autobiographical comics. New York, USA: Bloomsbury Academic.

McCloud, S. (1994). Understanding comics. New York: Harper.

Refaie, E. E. (2012). Autobiographical comics: Life writing in pictures. Jackson: University Press of Mississippi.

Tolmie, J. (2013). Drawing from life: Memory and subjectivity in comic art. Jackson: University Press of Mississippi.

White, M. (2017). Review of One! Hundred! Demons!. Retrieved August 24, 2018, from http://www.multiversitycomics.com/reviews/one-hundred-demons-review/

Whitlock, G. (2006). Autographics: The Seeing "I" of the Comics. MFS Modern Fiction Studies, 52(4), 965-979. Johns Hopkins University Press. Retrieved August 26, 2018, from Project MUSE database. 